\title{
LEVELS OF PESTICIDE RESIDUES AND METABOLITES IN SOIL AT VIKUGE FARM, KIBAHA DISTRICT, TANZANIA - A CLASSIC CASE OF SOIL CONTAMINATION BY OBSOLETE PESTICIDES
}

\author{
MA Kishimba and MJ Mihale \\ Chemistry Department, University of Dar es Salaam \\ P.O. Box 35061, Dar es Salaam, Tanzania
}

\begin{abstract}
ABS T RACT
The paper reports on the state of soil contamination by obsolete pesticides at Vikuge State Farm, Coast Region, Tanzania, where, in 1986, a $170 \mathrm{~m}^{3}$ "donation" of partially expired pesticides were stored in an open shed that eventually collapsed. Analyses of soil samples collected in 2000 from the old storage site at the farm for 80 different pesticide residues and metabolites have revealed alarmingly high concentrations of pesticide residues to qualify Vikuge as one of the most contaminated sites in the world. Most of the residues found in the soil at high concentrations were organochlorines, their concentrations being up to $282,000 \mathrm{mg} / \mathrm{kg}$ dry weight for total DDT (28.2\% by mass). Commercial formulations contain only between 5 and $10 \%$ DDT. The concentrations of $\mathrm{\Sigma HCH}$ were up to $63,360 \mathrm{mg} / \mathrm{kg}(6.4 \%$ by dry mass). A herbicide, pendimethalin [N-(1-ethylpropyl)-2,6-dinitro-3,4-xylidine], was also found at concentrations up to $40,900 \mathrm{mg} / \mathrm{kg}$ dry weight (4\% by mass). As expected, higher concentrations of the residues were found in the surface soil samples and the concentrations of the residues were decreased with increasing depth and distance from the point source. Immediate decontamination of this site is highly recommended.
\end{abstract}

\section{INTRODUCTION}

Obsolete pesticides no longer be used and therefore require disposal (Betlem et al. 1998, FAO 2001a). Although such pesticides are a common problem globally, they pose a more serious threat not only to the environment, but also to public health in African countries and the rest of the third world countries because these countries do not have the resources necessary for the safe disposal of these hazardous wastes. The amount of obsolete pesticides stocks in Africa is currently estimated to be more than 20,000 tonnes; with only seven countries including Tanzania, having more than 1,000 tonnes (FAO 2001b, Basel Convention 2001). They include large quantities of internationally banned organochlorine pesticides such as DDT, dieldrin, hexachlorocyclohexane $(\mathrm{HCH})$, and highly toxic organophosphorous insecticides such as parathion and dichlorvos (FAO, 1998). The majority of obsolete pesticides stocks in Tanzania are leftovers of pesticide donations (Betlem et al. 1998). Whilst most of the donations were genuine, some might have been opportunities to dump unwanted pesticides into poor and unsuspecting countries (FAO 2001a), as is apparent for the Vikuge case.

In 1986 , Greece donated $170 \mathrm{~m}^{3}$ of partly expired pesticides to the government of Tanzania through the Ministry of Agriculture. Without prior arrangements, the consignment was transported to Vikuge Farm for temporary storage before distribution to farmers (Betlem et al. 1998). The consignment was in poor condition and in damaged packages. Besides, most of the labels on containers were written in Greek, strongly indicating that the pesticides were intended for use locally in Greece. The consignment was stored in an open shed with an earthen floor. In 1993, the shed collapsed and the pesticides were exposed to direct sunlight, wind and rain. Though they were eventually collected and re-stored in a new building specially built for the purpose in 1998, the ground surface at the old 
storage site was still completely bare at the time of sampling in May - August 2000.

Vikuge Farm, besides being a storage site, is a hay production centre, with hay being grown within a radius of 100 metres from the old storage site. The hay is mostly sold to dairy farms in Dar es Salaam and Coast Regions. Villagers grow food crops for their own use such as maize and rice on the lowland areas that become periodically flooded with flowing water emanating from the high-rise areas including the old storage site. The present study reports the concentrations and distribution of pesticide residues in soil samples collected in March and August 2000, from the point source at Vikuge Farm, Coast Region and its immediate environs.

\section{METHODS \\ Materials}

All the reagents and solvents used were of analytical grade and included eighty (80) different pesticide standards ordered from Dr. Ehrenstorfer GmbH (Ausburg, Germany). Working standard solutions were made by dilution of the stock standards and mixtures of standards of different concentrations were used in most cases for the screening of the pesticide residues and metabolites. All volumetric glassware used was teflon stoppered. Varian Star 3400 and Hewlett Packard 5890A gas chromatographs equipped with ${ }^{63} \mathrm{Ni}$ Electron Capture, (EC) and Nitrogen-Phophorous, (NP) detectors were used for analysis.

\section{Sampling}

Soil samples were collected from Vikuge Farm, Kibaha district, Coast Region, Tanzania (Figure 1).

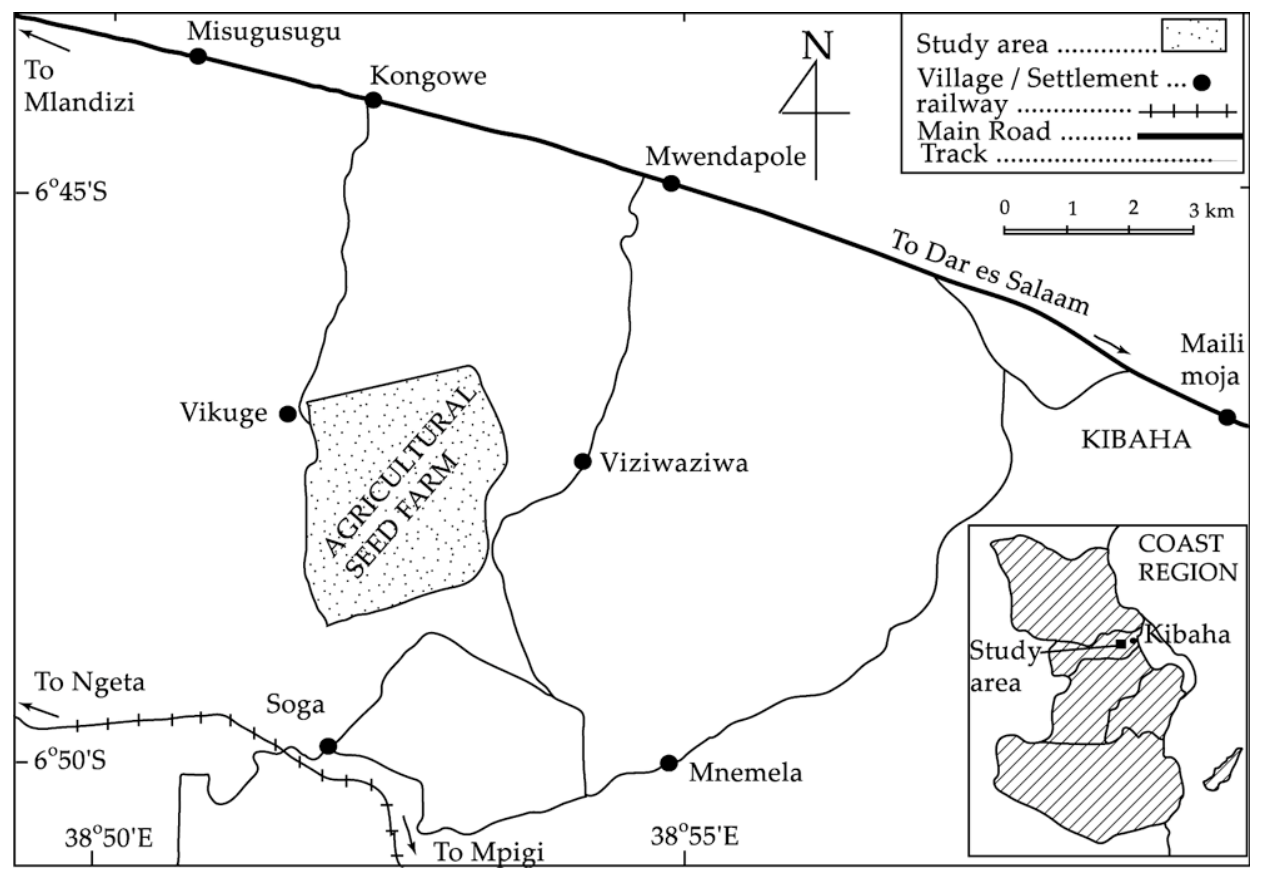

Figure 1 Map showing the Vikuge Study Area, Coast region, Tanzania 
The soil samples were collected in March and August 2000. Samples were collected at the point source, $20 \mathrm{~m}$ and $50 \mathrm{~m}$ away from the point source, downhill. At each of these sub-locations, samples were taken at the surface (up to $5 \mathrm{~cm}$ deep) and at depths of $20 \mathrm{~cm}$ and $50 \mathrm{~cm}$. Samples were taken using a hand hoe and a spade. The samples were wrapped in aluminium foil, put into plastic bags and kept frozen until extraction. A total of 7 sampling points were established: five points were within the point source and other two $(20 \mathrm{~m}$ and $50 \mathrm{~m})$, downhill, away from the source.

\section{Extraction}

Extraction of pesticides in soil samples was performed as per Åkerblom (1995). To a stoppered flask containing $20 \mathrm{~g}$ sample, 0.2 $\mathrm{M}$ ammonium chloride solution $(14 \mathrm{ml})$ was added. The mixture was swirled for two minutes after which the flask and its contents were left to stand for 15 minutes before addition of cyclohexane:acetone $(1: 1$, $100 \mathrm{ml}$ ). The flask was then tightly stoppered and vigorously shaken for one minute, and then less vigorously after every ten minutes for one hour. The contents were subsequently subjected to ultrasound for ten minutes. Distilled water was added cautiously until the organic layer rose to the neck of the flask. The organic phase was then quantitatively Pasteur pipetted into an E-flask that contained oven pre-dried anhydrous sodium sulphate ( $c a .15 \mathrm{~g}$ ) after which the contents were decanted through a plug of glass wool into an evaporation flask. The remaining sodium sulphate was rinsed with acetone $(30 \mathrm{ml})$ and again decanted through the same glass wool plug. The resulting organic layer was concentrated to appropriate volumes.

\section{Clean up}

Most of the extracts required high dilutions of up to $10,000,000$, which by itself was the major clean up procedure. Acid and alkali treatments were also employed as described by Åkerblom (1995). In the acid treatment, concentrated sulphuric acid (1 ml) saturated with cyclohexane was added to the extract $(2 \mathrm{ml})$ in a test tube. The mixture was then swirled for one minute before centrifugation after which the organic layer was carefully transferred using a Pasteur pipette into another test tube and diluted with cyclohexane:acetone (9:1, 2 $\mathrm{ml}$ ) ready for analysis.

In alkali treatment, potassium hydroxide (two pellets) was dissolved in a mixture of water $(0.1 \mathrm{ml})$ and $99 \%$ ethanol $(2 \mathrm{ml})$ in a test tube. The extract $(1 \mathrm{ml})$ in cyclohexane was added into the mixture and placed in a water bath at $50{ }^{\circ} \mathrm{C}$ for 30 minutes, followed by cooling at room temperature. Sodium chloride-phosphoric acid solution $(5 \mathrm{ml})$, (prepared by dissolving $12 \mathrm{~g}$ of sodium chloride in a litre of $0.1 \mathrm{M}$ orthophosphoric acid), was added and the mixture was shaken and centrifuged. The organic layer was transferred into a round bottomed flask, followed by changing the solvent to cyclohexane:acetone $(9: 1)$ for $\mathrm{GC}$ analysis.

\section{Analysis and quantification}

Analysis for the residues and metabolites was done as described by Åkerblom (1995). Varian Star 3400 and Hewlett Packard 5890A gas chromatographs equipped with ${ }^{63} \mathrm{Ni}$ Electron Capture (EC) and NitrogenPhophorous (NP) detectors were used for the analysis. SE-30 and OV-1701 megabore columns $(30 \mathrm{~m} \times 0.32 \mathrm{~mm} \times 0.5 \mu \mathrm{m})$ were used in each detector. Nitrogen was used as both a carrier and make up gas in the ECD at a flow rate of $30 \pm 1 \mathrm{ml} / \mathrm{min}$. In the NPD, helium was used as a carrier gas at a flow rate of $0.5-1 \mathrm{ml} / \mathrm{min}$ and nitrogen, at a flow rate of $29 \pm 1 \mathrm{ml} / \mathrm{min}$, was used as the make up gas. The temperature programme was $90{ }^{\circ} \mathrm{C}$ held for $1 \mathrm{~min}, 30{ }^{\circ} \mathrm{C} / \mathrm{min}$ to 180 ${ }^{\circ} \mathrm{C}, 4{ }^{\circ} \mathrm{C} / \mathrm{min}$ to $260{ }^{\circ} \mathrm{C}$ held for 12 minutes. The injector and detector temperatures were $250{ }^{\circ} \mathrm{C}$ and $300{ }^{\circ} \mathrm{C}$, respectively. Identification of residues was effected by running samples and external reference standards in $\mathrm{GC}$ and then comparing the chromatograms. A peak was not considered 
relevant unless it appeared in both columns in a given detector. The method average detection limits are given in Table 1.

\begin{tabular}{|c|c|c|c|}
\hline Table 1 & $\begin{array}{l}\text { Averag } \\
\text { Limits } \\
\times 10^{-2}\end{array}$ & $\begin{array}{l}\text { Method } \\
(\mathrm{mg} / \mathrm{kg} \text { dry }\end{array}$ & $\begin{array}{l}\text { etection } \\
\text { weight) }\end{array}$ \\
\hline$\alpha-\mathrm{HCH}$ & 3 & heptachlor & 0.05 \\
\hline$\beta-\mathrm{HCH}$ & 2 & $\begin{array}{l}\text { Heptachlor } \\
\text { epoxide }\end{array}$ & 0.06 \\
\hline$\gamma-\mathrm{HCH}$ & 0.1 & $p, p^{\prime}-\mathrm{DDE}$ & 0.06 \\
\hline$\delta-\mathrm{HCH}$ & 0.1 & $p, p^{\prime}-\mathrm{DDD}$ & 0.7 \\
\hline Aldrin & 0.08 & $o, p^{\prime}-\mathrm{DDT}$ & 2 \\
\hline $\begin{array}{l}\text { P'methalin } \\
\text {-chlordane }\end{array}$ & $\begin{array}{l}4.5 \\
0.05\end{array}$ & $p, p^{\prime}-\mathrm{DDT}$ & 10 \\
\hline
\end{tabular}

Recoveries of residues were in the range $59-80$ $\%$ for $\mathrm{HCH}$ and $70-99 \%$ for DDT which is within the acceptable range (Åkerblom 1995).

\section{RESULTS AND DISCUSSION}

Organochlorines were the most frequently detected pesticides in the soil samples. These included the $\mathrm{HCH}$ isomers a-, b-, g-, d- HCH and DDT isomers, $p, p^{\prime}$-DDT and $o, p^{\prime}$-DDT, and metabolites, $p, p$ '-DDE and $p, p$ '-DDD. The total organochlorines concentrations were up to $345,000 \mathrm{ppm}$ (34.6\%, dry mass). Pendimethalin [N-(1ethylpropyl)-2,6-dinitro-3,4-xylidine], an organic herbicide was also found at concentrations ranging from $39.9 \mathrm{mg} / \mathrm{kg}$ to $40,900 \mathrm{mg} / \mathrm{kg}$ dry weight.

\section{Distribution of $\mathrm{HCH}$ residues in soil}

The a-HCH and b-HCH isomers were found in surface samples in the range of 230$49,700 \mathrm{mg} / \mathrm{kg}$ (i.e., up to $5 \%$ ) and 340 $6,370 \mathrm{mg} / \mathrm{kg}$ (i.e., up to $0.6 \%$ ) dry weight respectively, representing over $70 \%$ of the samples analysed (Table 2). The isomers g$\mathrm{HCH}$ and $\mathrm{d}-\mathrm{HCH}$ were detected in the range of $80-7,200 \mathrm{mg} / \mathrm{kg}$ (i.e., up to $0.7 \%$ ) and $90-2,360 \mathrm{mg} / \mathrm{kg}$ (i.e., up to $0.2 \%$ ) dry weight, respectively. The general trend displayed by the concentrations of $\mathrm{HCHs}$ in the surface samples was $\alpha-\mathrm{HCH}>\beta-\mathrm{HCH}>$ $\gamma-\mathrm{HCH}>\delta-\mathrm{HCH}$.

Table 2 Concentrations of $\mathrm{HCH}$ residues in surface soil samples

\begin{tabular}{|c|c|c|c|c|c|c|c|}
\hline \multirow{2}{*}{\multicolumn{2}{|c|}{$\begin{array}{l}\text { Sampling } \\
\text { Point }\end{array}$}} & \multicolumn{5}{|c|}{ Concentration (mg/kg dry weight) $x 10^{3}$} & \multirow[b]{2}{*}{$\begin{array}{l}\alpha-\mathrm{HCH} / \gamma-\mathrm{HCH} \\
\text { ratio }\end{array}$} \\
\hline & & $\alpha-\mathrm{HCH}$ & $\beta-\mathrm{HCH}$ & $\gamma-\mathrm{HCH}$ & $\delta-\mathrm{HCH}$ & $\Sigma \mathrm{HCH}$ & \\
\hline \multirow{5}{*}{$\begin{array}{l}\text { Onsite } \\
\text { points }\end{array}$} & $\mathrm{A}$ & $49.7 \pm 0.08$ & $4.1 \pm 0.15$ & $7.2 \pm 0.04$ & $2.36 \pm 0.05$ & 63.36 & 6.9 \\
\hline & B & $34.2 \pm 0.08$ & $4.89 \pm 0.15$ & $5.05 \pm 0.04$ & $0.78 \pm 0.05$ & 44.92 & 6.8 \\
\hline & $\mathrm{C}$ & $0.23 \pm 0.08$ & $1.77 \pm 0.15$ & $0.08 \pm 0.04$ & $0.19 \pm 0.05$ & 2.27 & 2.9 \\
\hline & $\mathrm{D}$ & $2.85 \pm 0.08$ & $0.34 \pm 0.15$ & $0.15 \pm 0.04$ & $0.09 \pm 0.05$ & 3.43 & 18.6 \\
\hline & $\mathrm{E}$ & $22.2 \pm 0.08$ & $6.37 \pm 0.15$ & $0.46 \pm 0.04$ & $0.21 \pm 0.05$ & 29.24 & 48.3 \\
\hline \multirow{2}{*}{$\begin{array}{l}\text { Away } \\
\text { Points } \\
\end{array}$} & $20 \mathrm{~m}$ & $1.13 \pm 0.08$ & $2.43 \pm 0.15$ & $<0.07$ & $<0.09$ & 3.56 & - \\
\hline & $50 \mathrm{~m}$ & $<0.15$ & $<0.3$ & $<0.07$ & $<0.09$ & - & - \\
\hline
\end{tabular}

In the $20 \mathrm{~cm}$ deep samples, $\alpha-\mathrm{HCH}$ and $\beta$ $\mathrm{HCH}$ isomers were detected in all the samples with concentrations ranging from $0.16 \mathrm{mg} / \mathrm{kg}$ to $3,800 \mathrm{mg} / \mathrm{kg}$ (i.e., up to $0.4 \%$ ) dry weight (Table 3 ) and Figure 2).
The $\gamma-\mathrm{HCH}$ and $\delta$-HCH isomers were not detected in some samples. In general the $\mathrm{HCH}$ concentrations trend was in the order; $\alpha-\mathrm{HCH}>\beta-\mathrm{HCH}>\delta-\mathrm{HCH}>\gamma-\mathrm{HCH}$. 
Table 3 Concentrations of $\mathrm{HCH}$ residues in soil samples at a depth of $20 \mathrm{~cm}$

\begin{tabular}{llllllll}
\hline \multirow{2}{*}{ Sampling Point } & \multicolumn{7}{c}{ Concentration (in mg/kg dry weight) } \\
\cline { 2 - 7 } & & $\alpha-\mathrm{HCH}$ & $\beta-\mathrm{HCH}$ & $\gamma$-HCH & $\delta$-HCH & $\Sigma \mathrm{HCH}$ & $\begin{array}{l}\alpha-\mathrm{HCH} / \gamma- \\
\mathrm{HCH} \text { ratio }\end{array}$ \\
\hline \multirow{2}{*}{ Onsite } & $\mathrm{A}$ & $3800 \pm 0.04$ & $590 \pm 0.1$ & $392 \pm 0.06$ & $296 \pm 0.07$ & 5078 & 9.7 \\
points & $\mathrm{C}$ & $1.81 \pm 0.04$ & $1.56 \pm 0.1$ & $2.23 \pm 0.06$ & $16 \pm 0.07$ & 21.59 & 0.8 \\
& $\mathrm{D}$ & $45 \pm 0.04$ & $32 \pm 0.1$ & $23 \pm 0.06$ & $144 \pm 0.07$ & 244 & 2 \\
& $\mathrm{E}$ & $0.22 \pm 0.04$ & $0.3 \pm 0.15$ & $0.19 \pm 0.06$ & $1.03 \pm 0.07$ & 1.76 & 1.2 \\
\hline Away & $20 \mathrm{~m}$ & $0.16 \pm 0.04$ & $0.39 \pm 0.1$ & $<0.12$ & $<0.13$ & 0.55 & - \\
points & $50 \mathrm{~m}$ & $<0.08$ & $<0.2$ & $<0.12$ & $<0.13$ & - & - \\
\hline
\end{tabular}

$\mathrm{HCH}$ residues were also detected in some of the samples at the depth of $50 \mathrm{~cm}$ indicating possible risk to ground water contamination (Table 4). The onsite samples had higher concentrations relative to away samples but much lower than those from the surface and the samples collected from a depth of 20 $\mathrm{cm}$.

Table 4 Concentrations of $\mathrm{HCH}$ residues in $50 \mathrm{~cm}$ deep soil samples

\begin{tabular}{|c|c|c|c|c|c|c|c|}
\hline \multicolumn{2}{|c|}{ Sampling Point } & \multicolumn{5}{|c|}{ Concentration (in mg/kg dry weight) } & \multirow[b]{2}{*}{$\begin{array}{l}\alpha-\mathrm{HCH} / \gamma- \\
\mathrm{HCH} \text { ratio }\end{array}$} \\
\hline & & $\alpha-\mathrm{HCH}$ & $\beta-\mathrm{HCH}$ & $\gamma-\mathrm{HCH}$ & $\delta-\mathrm{HCH}$ & $\Sigma \mathrm{HCH}$ & \\
\hline \multirow{5}{*}{$\begin{array}{l}\text { Onsite } \\
\text { points }\end{array}$} & $\mathrm{A}$ & $<0.08$ & $<0.3$ & $<0.1$ & $<0.13$ & - & - \\
\hline & B & $0.26 \pm 0.04$ & $0.65 \pm 0.1$ & $0.2 \pm 0.05$ & $<0.13$ & 1.19 & 0.93 \\
\hline & $\mathrm{C}$ & $0.89 \pm 0.04$ & $0.38 \pm 0.1$ & $<0.1$ & $0.16 \pm 0.08$ & 1.43 & - \\
\hline & $\mathrm{D}$ & $0.17 \pm 0.04$ & $0.3 \pm 0.1$ & $0.2 \pm 0.05$ & $1.6 \pm 0.08$ & 2.31 & 0.71 \\
\hline & $\mathrm{E}$ & $0.53 \pm 0.04$ & $0.68 \pm 0.1$ & $<0.1$ & $0.96 \pm 0.08$ & 2.17 & - \\
\hline \multirow{2}{*}{$\begin{array}{l}\text { Away } \\
\text { points }\end{array}$} & $20 \mathrm{~m}$ & $0.2 \pm 0.04$ & $<0.3$ & 0.1 & $<0.13$ & 0.3 & 2 \\
\hline & $50 \mathrm{~m}$ & $<0.08$ & $<0.3$ & $<0.1$ & $<0.13$ & - & - \\
\hline
\end{tabular}

Table 5 Concentrations of $\mathrm{HCH}$ residues as compared to depth.

\begin{tabular}{lllll}
\hline \multirow{2}{*}{ Depth } & \multicolumn{4}{l}{ Mean concentrations (mg/kg dry weight) for onsite samples } \\
\cline { 2 - 5 } & $\alpha-\mathrm{HCH}$ & $\beta$-HCH & $\gamma$-HCH & $\delta$-HCH \\
\hline surface & $21856.6 \pm 0.08$ & $3493.2 \pm 0.15$ & $2588.8 \pm 0.05$ & $727.8 \pm 0.05$ \\
$20 \mathrm{~cm}$ & $798.2 \pm 0.04$ & $124.8 \pm 0.1$ & $83.5 \pm 0.06$ & $91.4 \pm 0.07$ \\
$50 \mathrm{~cm}$ & $0.37 \pm 0.04$ & $0.4 \pm 0.15$ & $0.11 \pm 0.08$ & $0.56 \pm 0.08$ \\
\hline
\end{tabular}

A comparison between the mean levels $\mathrm{HCH}$ residues at different depths for the onsite samples are given in Table 5

The results from the pesticide residues' determinations in the surface soil revealed very high pesticide levels. The $\alpha-\mathrm{HCH}$ isomer was detected in high amounts, especially in samples from the point source, resulting to high $\alpha-\mathrm{HCH} / \gamma-\mathrm{HCH}$ ratios. Ratios from 2.9 to 48.3 were obtained (Table 2), with an average ratio of 16.78 for surface soil samples within the old storage site. These ratios are three times more than the ratio of the isomers in the technical $\mathrm{HCH}$ commercially available (about 5.3). This is clearly indicative of contamination by a technical $\mathrm{HCH}$ product. There are eight 
(8) possible isomers of $\mathrm{HCH}$, but it is usually the $\alpha-, \beta-, \gamma-$ and $\delta$-isomers that are of importance in the technical product (Tomlin 2000). The g-isomer (lindane) is the only isomer with insecticidal properties. In Western Europe and North America, the use of such technical products ceased in the 1970 s and instead purified lindane has been used (Environment Canada 2000). Technical $\mathrm{HCH}$, however, is still used in some developing countries.

All the $\mathrm{HCH}$ isomers are stable and have the potential to be transported over long distances and to bioaccumulate in organisms. In the environment, lindane is potentially transformed into a variety of chemicals most of which are volatile. These include $\gamma$-pentachlorocyclohex-1-ene, $\gamma$ 3,4,5,6-tetrachlorocyclohex-1-ene, $\alpha-\mathrm{HCH}$, $\beta-\mathrm{HCH}$ and $\delta-\mathrm{HCH}$ (Sang et al. 1999). However, the thermodynamically most favourable structure is the a-isomer, which constitutes up to $70 \%$ of the $\mathrm{HCH}$ in the technical product. The $\beta$-isomer, constituting only $6-7 \%$ in technical $\mathrm{HCH}$, is the most persistent in the environment. Thus $\beta-\mathrm{HCH}$, may accumulate relative to other isomers in an aged technical product. $\delta-\mathrm{HCH}$ is rarely found in the environment, except when there is a fresh release of the technical product.

The presence of high $\alpha-\mathrm{HCH}$ residues with respect to $\gamma-\mathrm{HCH}$ in soil samples can be attributed to two major factors; the different degradation rates and variable physicochemical properties of the isomers. $\mathrm{HCH}$ isomers have different degradation rates under environmental conditions. The difference in degradation rates of $\mathrm{HCH}$ isomers could have contributed to the variable accumulation of the isomers in this area. The isomers also vary in their physicochemical properties. $\alpha$-HCH has a Henry's Law Constant of $0.524 \mathrm{~Pa} \mathrm{~m} 3 / \mathrm{mol}$ while that for lindane is $0.257 \mathrm{~Pa} \mathrm{~m} 3 / \mathrm{mol}$ at 20
${ }^{\circ} \mathrm{C}$ (Tomlin 2000). This indicates relatively high water solubility of lindane and its tendency to partition faster from a gas phase into the water phase. Therefore during global distillation of $\mathrm{HCH}$ isomers, lindane is readily removed from the troposphere by rain, leaving proportionally higher levels of $\alpha-\mathrm{HCH}$ (Sang et al. 1999). Besides the significant influence of temperature, humidity and solar radiation on the rapid dissipation of $\mathrm{HCH}$ isomers in a tropical coastal environment like the Vikuge environment, there are still high levels of the residues detected in soil. Though $\alpha$ $\mathrm{HCH}$ is expected to be the fastest isomer to dissipate from the soil due to its high vapour pressure and hence high volatilisation rate, it has been detected in soil samples at very high levels. This again is an indication of the large amount of the technical HCH spilled in the area. Tables 2 5 show that the levels of $\mathrm{HCH}$ isomers were decreasing with increasing distance from the surface. This observation is consistent with the hypothesis that $\mathrm{HCH}$ isomers will stay on the upper layers of the soil; and there is little movement of the isomers to lower soil layers (Sang et al. 1999).

Distribution of DDT residues in soil

The pesticide residue analysis results showed the presence of $p, p^{\prime}$-DDT and $p, p^{\prime}$ DDD in more than $86 \%$ of the samples, with concentrations from 5,200 to 172,000 $\mathrm{mg} / \mathrm{kg}$ dry weight (i.e., up to $17.2 \%$ ) for $p, p$-DDT and from 4,700 to $69,600 \mathrm{mg} / \mathrm{kg}$ dry weight (i.e., up to $7 \%$ ) for $p, p$ '-DDD (Table 6). The $p, p^{\prime}$-DDE and $o, p$ '-DDT concentrations ranges were $140-4,050$ $\mathrm{mg} / \mathrm{kg}$ and 2,000 - 36,100 mg/kg dry weight, respectively. A concentration trend in the order of $p, p$ '-DDT $>p, p^{\prime}$-DDD $>$ $o, p^{\prime}$-DDT $>p, p$ '-DDE was observed in surface samples. These figures for $p, p$ '-DDT are higher than the concentrations of in commercial formulations, which are usually between 5 and $10 \%$. 
Table 6 Concentrations of DDT residues in surface soil samples

\begin{tabular}{llllllll}
\hline \multirow{2}{*}{ Sampling Point } & \multicolumn{5}{c}{ Concentration (in mg/kg dry weight) $\mathbf{~ 1 0} \mathbf{3 0}^{\mathbf{3}}$} & \\
\cline { 2 - 6 } & & $p, p^{\prime}$-DDE & $p, p^{\prime}$-DDD & $o, p^{\prime}$-DDT & $p, p^{\prime}$-DDT & $\Sigma$ DDT & DDE/DDT \\
\hline \multirow{2}{*}{ Onsite } & $\mathrm{A}$ & 4.05 & 69.6 & 36.1 & 172 & 281.75 & 0.02 \\
points & $\mathrm{B}$ & 0.31 & 21.5 & 7.45 & 30 & 59.26 & 0.01 \\
& $\mathrm{C}$ & 0.7 & 12.24 & 6.6 & 13.8 & 33.34 & 0.03 \\
& $\mathrm{D}$ & 0.14 & 4.7 & 2 & 5.2 & 12.04 & 0.02 \\
& $\mathrm{E}$ & 0.53 & 41.6 & 13.46 & 65.25 & 120.84 & 0.01 \\
\hline Away & $20 \mathrm{~m}$ & 0.27 & 12.1 & 3.76 & 16.82 & 32.95 & 0.01 \\
points & $50 \mathrm{~m}$ & $<0.1$ & 0.94 & $<1.03$ & $<1.6$ & 0.94 & - \\
\hline
\end{tabular}

The concentrations of $\Sigma$ DDT and of individual DDT residues decreased with increasing distance from the site. In surface samples, the DDT residue concentrations were higher than the $\mathrm{HCH}$ residue concentrations.

DDT residues and metabolites were detected in all the $20 \mathrm{~cm}$-deep samples (Table 7). The concentrations ranged between $0.11 \mathrm{mg} / \mathrm{kg}$ $\left(p, p^{\prime}\right.$-DDE) and $14,800 \mathrm{mg} / \mathrm{kg}$ dry weight $(p, p$ '-DDT). Concentrations of the DDTs in $20 \mathrm{~cm}$-deep samples were of the trend: $p, p$ '$\mathrm{DDT}>o, p^{\prime}-\mathrm{DDT}>p, p^{\prime}-\mathrm{DDD}>p, p^{\prime}-\mathrm{DDE}$. The concentrations of the DDTs in these samples were generally higher than those of $\mathrm{HCHs}$, but lower than those of DDTs in the surface samples.

Table 7 Concentrations of DDT residues in $20 \mathrm{~cm}$-deep soil samples.

\begin{tabular}{|c|c|c|c|c|c|c|c|}
\hline \multirow{2}{*}{\multicolumn{2}{|c|}{ Sampling Point }} & \multirow{2}{*}{\multicolumn{5}{|c|}{ Concentration (in mg/kg dry weight) }} & \multirow{3}{*}{$\begin{array}{l}\text { DDE/DD } \\
\text { T ratio } \\
0002\end{array}$} \\
\hline & & & & & & & \\
\hline \multirow{5}{*}{$\begin{array}{l}\text { Onsite } \\
\text { points }\end{array}$} & $\bar{A}$ & $\begin{array}{l}p, p^{\prime}-\mathrm{DDE} \\
40 \pm 0.05\end{array}$ & $\begin{array}{l}p, p ' \text {-DDD } \\
773 \pm 0.05\end{array}$ & $o, p^{\prime}$-DDT & $14800 \pm 0.5$ & 18057 & \\
\hline & $\mathrm{B}$ & $<0.1$ & $0.27 \pm 0.05$ & $0.33 \pm 0.1$ & $2.8 \pm 0.5$ & 3.4 & - \\
\hline & $\mathrm{C}$ & $14 \pm 0.05$ & $459 \pm 0.05$ & $150 \pm 0.1$ & $820 \pm 0.5$ & 1443 & 0.01 \\
\hline & $\mathrm{D}$ & $22 \pm 0.05$ & $304 \pm 0.05$ & $455 \pm 0.1$ & $1900 \pm 0.5$ & 2681 & 0.01 \\
\hline & $\mathrm{E}$ & $0.14 \pm 0.05$ & $0.64 \pm 0.05$ & $4.71 \pm 0.1$ & $7.96 \pm 0.5$ & 13.45 & 0.01 \\
\hline \multirow{2}{*}{$\begin{array}{l}\text { Away } \\
\text { points }\end{array}$} & $20 \mathrm{~m}$ & $0.11 \pm 0.05$ & $0.41 \pm 0.05$ & $0.98 \pm 0.1$ & $5.2 \pm 0.5$ & 6.7 & 0.02 \\
\hline & $50 \mathrm{~m}$ & $1.24 \pm 0.05$ & $1.67 \pm 0.05$ & $7.01 \pm 0.1$ & $32.41 \pm 0.5$ & 42.33 & 0.03 \\
\hline
\end{tabular}

DDT and its metabolites were also detected in $50 \mathrm{~cm}$-deep soil samples with concentrations ranging from $0.21 \mathrm{mg} / \mathrm{kg}$ ( $\left.p, p^{\prime}-\mathrm{DDE}\right)$ to $33 \mathrm{mg} / \mathrm{kg}$ dry weight $\left(o, p^{\prime}-\right.$ DDT) (Table 8). This shoewed nearly the same order in the concentration trend: $p, p^{\prime}-$ $\mathrm{DDT}>o, p^{\prime}$-DDT $=p, p^{\prime}-\mathrm{DDD}>p, p^{\prime}$-DDE as observed in the surface and $20 \mathrm{~cm}$-deep samples. DDT residues, (o, $p$ '-DDT and $p, p^{\prime}$ DDT), showed higher concentrations compared to the metabolites, $(p, p$ '-DDE and $p, p$ '-DDD). The concentrations of pesticide residues in the $50-\mathrm{cm}$ deep samples were lower than those of both the surface and 20cm deep samples. 
Kishimba and Mihale - Levels of pesticide residues and metabolites in soil ...

Table 8 Concentrations of DDT residues in 50-cm deep soil samples

\begin{tabular}{llllllll}
\hline \multirow{2}{*}{ Sampling Point } & \multicolumn{5}{c}{ Concentration (in mg/kg dry weight) } & \\
\cline { 3 - 6 } & & $p, p^{\prime}$-DDE & $p, p^{\prime}$-DDD & $o, p^{\prime}$-DDT & $p, p^{\prime}$-DDT & $\Sigma$ DDT & $\begin{array}{l}\text { DDE/DDT } \\
\text { ratio }\end{array}$ \\
\hline \multirow{2}{*}{ Onsite } & $\mathrm{A}$ & $<0.14$ & $<0.14$ & $<0.82$ & $<2$ & - & - \\
points & $\mathrm{B}$ & $0.3 \pm 0.07$ & $0.43 \pm 0.07$ & $<0.82$ & $2.62 \pm 1.0$ & 3.76 & 0.1 \\
& $\mathrm{C}$ & $0.16 \pm 0.07$ & $1.39 \pm 0.07$ & $1.59 \pm 0.41$ & $9.39 \pm 1.0$ & 12.53 & 0.01 \\
& $\mathrm{D}$ & $2.25 \pm 0.07$ & $18 \pm 0.07$ & $33 \pm 0.41$ & $<2$ & 53.25 & 0.07 \\
& $\mathrm{E}$ & $0.21 \pm 0.07$ & $3.6 \pm 0.07$ & $5.97 \pm 0.04$ & $27 \pm 1.0$ & 36.78 & 0.01 \\
\hline Away & $20 \mathrm{~m}$ & $<0.14$ & $0.31 \pm 0.07$ & $<0.82$ & $<2$ & 0.31 & - \\
points & $50 \mathrm{~m}$ & $<0.14$ & $0.29 \pm 0.07$ & $<0.82$ & $<2$ & 0.29 & - \\
\hline
\end{tabular}

Table 9 Concentrations of DDT residues with respect to depth.

\begin{tabular}{lcccc}
\hline \multirow{2}{*}{ Depth } & \multicolumn{4}{c}{ Mean concentrations (in mg/kg dry weight) for $\mathbf{A}, \mathbf{B}, \mathbf{C}, \mathbf{D}$ and E } \\
\cline { 2 - 5 } & $p, p^{\prime}$-DDE & $p, p^{\prime}$-DDD & $o, p^{\prime}$-DDT & $p, p^{\prime}$-DDT \\
\hline surface & $1145.8 \pm 0.05$ & $29928 \pm 0.07$ & $13122 \pm 0.5$ & $57250 \pm 0.5$ \\
$\mathbf{2 0} \mathbf{~ c m}$ & $15.3 \pm 0.05$ & $307.4 \pm 0.05$ & $610.8 \pm 0.1$ & $3506.2 \pm 0.5$ \\
$\mathbf{5 0} \mathbf{~ c m}$ & $0.58 \pm 0.07$ & $4.7 \pm 0.07$ & $8.2 \pm 0.04$ & $7.8 \pm 1.0$ \\
\hline
\end{tabular}

Table 9 gives the concentrations of different DDT residues at different depths.

The high $\Sigma$ DDT (that is $p, p^{\prime}-\mathrm{DDE}+p, p^{\prime}-$ $\mathrm{DDD}+o, p^{\prime}$-DDT $+p, p^{\prime}$-DDT) in each of the onsite soil samples (Tables 6-8) suggests that a large amount of DDT leaked onto the soil at the area. The percentage of $p, p$ '-DDT was higher than those of the other DDT isomer and metabolites, supporting the hypothesis that a large quantity of technical grade DDT was stored at the old storage area (the point source). The DDE/DDT ratios of less than one in the onsite samples (Table 6) suggest that there has been little or no degradation of DDT to its metabolites such as DDD and DDE in surface soil. A ratio larger than 3 is normally expected for aged mixtures in the environment (Tomlin 2000).

Higher DDD concentrations as compared to those of DDE in surface samples (6) suggests a possibility of the consignment containing DDD as a pesticide of its own (Tomlin 2000). DDD, has been observed to be persistent in soil, sediment and water for as long as 190 years (WWF 1999). It is also possible that some of the DDD residues have been formed as a result of degradation of DDT during injection in the GC. This is supported by experimental evidence for the DDT conversion to it metabolites, DDD and DDE, depending on the matrix coextractives present in the analyte, some of which appear to catalyse the process (Miglioranza et al 1999).

While there is literature support (Lalah et al 1994, Wandiga 1996, Lalah \& Wandiga 1998) for significantly more rapid pesticide dissipation from tropical than under temperate conditions largely as a result of enhanced volatility and microbial degradation, soils are often dry which significantly delays, or even stops any transformation (Brooks et al 1999). Vikuge has a sandy loam type of soil $(84.5 \%$ sand, $11.3 \%$ clay and $2.7 \%$ silt) with very low organic matter content $(1.5 \%)$. For mobile and/or persistent pesticides, this has serious implications for ground water contamination, particularly for high water table areas like the Tanzanian coastal areas. On the other hand, the acidic $(\mathrm{pH}$ 3.9) nature of the soil at Vikuge significantly 
hampers the DDT dehydrochlorination reaction in the soil, hence the high DDT levels and low DDE levels in the study area.

\section{Other pesticide residues}

Other organochlorines detected in soil samples were the cyclodienes: g-chlordane, heptachlor and aldrin. Whereas g-chlordane was detected in more than $70 \%$ of the samples, heptachlor and aldrin were detected in less than $15 \%$ of the samples only. $\gamma$ Chlordane was detected in most of the onsite samples, with concentration ranging from $49 \mathrm{mg} / \mathrm{kg}$ dry weight to $822 \mathrm{mg} / \mathrm{kg}$ dry weight. Heptachlor and aldrin were detected at concentrations of $36 \mathrm{mg} / \mathrm{kg}$ and $107 \mathrm{mg} / \mathrm{kg}$ dry mass, respectively. On the other hand, the pre-emergence organic herbicide, pendimethalin was detected in one onsite surface soil sample at a concentration of $40,900 \mathrm{mg} / \mathrm{kg}$ dry weight. Pendimethalin is reported to be fairly immobile and persistent in soil, with its leaching potential being very low (WHO 1993). This may explain its being found in a single surface soil sample. The quarternary ammonium herbicides: paraquat and diquat, were also analysed for but found to have concentrations below the method detection limit $(1.1 \mathrm{mg} / \mathrm{kg}$ dry weight $)$ in the surface soil samples.

Soils exposed to hazardous chemicals like these pesticides can be severely damaged by alteration of their physical and chemical properties and thus reducing the ability to support plants (Manahan 2001) as well as other living organisms. This is evidently clear in the study area where there has been no plant growth and the soil has remained sterile for more than fifteen years now.

\section{CONCLUSION}

There was a presence of high levels of pesticide residues and metabolites in the top-soil, up to 2.8 times the strongest commercial formulation of DDT, and at different depths at the old storage suet at Vikuge farm, Kibaha district. This advocates for more serious consequences of even more dispersion of the pesticide residues and pollution of ground water in the area. The pesticides were stored at Vikuge in 1986, whereas the samples analysed were taken in 2000. The prevalence of such high levels of pesticide residues raises questions like "What was the situation fifteen years ago, after the first rains? How much of the water-soluble pesticides contaminated drinking water and what were the consequences". Whatever the case, the old storage site at Vikuge is probably the most contaminated site in the world and immediate decontamination measures need to be undertaken, with the hope that a similar situation shall never again arise in Tanzania, Africa and the world.

\section{ACKNOWLEDGEMENT}

This work was supported totally by Sida/SAREC, first of all by a scholarship to MAJM and through the Agrochemical Pesticides Project of the Faculty of Science, UDSM. The support is humbly acknowledged.

\section{REFERENCES}

Åkerblom M (1995). Guidelines for environmental monitoring of pesticide residues in the SADC Region. SADC ELMS. Sweden.

Basel Convention, (2001) Basel Convention Series, Basel, Switzerland

Betlem JL, Kijazi P. and Msangi S. 1998 Obsolete pesticides and veterinary wastes in Tanzania, Chemical Waste Management in Tanzania Project. Volume I, National Environment Management Council (NEMC) Dar es Salaam.

Brooks GT and Roberts TP 1999 "Pesticide Chemistry and Bioscience: The FoodEnvironment Challenge" Royal Society of Chemistry, London.

Environment Canada 2000, Global HCH emissions, Canadian Global Emmisions Interpretation Centre, Air Quality Research Branch, Toronto 
FAO 2001a Pesticide disposal: Prevention and disposal of obsolete pesticides, FAO Pesticide Disposal Series No 6, Rome.

FAO 2001b Baseline study on the problem of obsolete pesticide stocks. FAO Pesticide Disposal Series No. 9, Rome.

FAO 1998 Pesticide management: prevention and disposal of obsolete pesticides. Rome.

Foreman WT and Gates PM 1997 Matrixenhanced degradation of $p, p^{\prime}$-DDT during gas chromatographic analysis: a consideration Environ. Sci. Technol., 31, 905-910.

Lalah JO Acholla FN Wandiga S O (1994) The fate of ${ }^{14} \mathrm{C}$-DDT in Kenyan tropical soils, J. Env. Scie. Health B29: (i) 5764.

Lalah J and Wandiga SO (1998) The fate and dissipation of surface applied 14 "C-DDE in a tropical soil. J. Toxic and Environ. Chem. 65: 9-16.
Wandiga SO (1996) Organochlorine pesticides: curse or blessing in tropical agriculture? in "Environment and Development" The Kenya National Academy of Sciences, Public Lecture Series.

Manahan SE 2001 Fundamentals of environmental chemistry 2nd Edition, CRC Press, Boca Raton, Carlifornia.

Miglioranza, KSB Moreno A de JE Moreno VJ Osterrieth ML and Escalante AH (1999) Environmental Pollution, 105: 91-99.

Sang S Petrovic S and Cuddeford V (1999). Lindane - a review of toxicity and environmental fate. WWF Canada.

Tomlin C.D.S (ed) 2000 The pesticide manual $12^{\text {th }}$ Edition, British Crop Protection Council.

WHO (1993) Guidelines for drinking water quality Second Edition Geneva

WWF (1999). Hazards and exposures associated with DDT and synthetic pyrethroids used for vector control, WWF. Canada. 